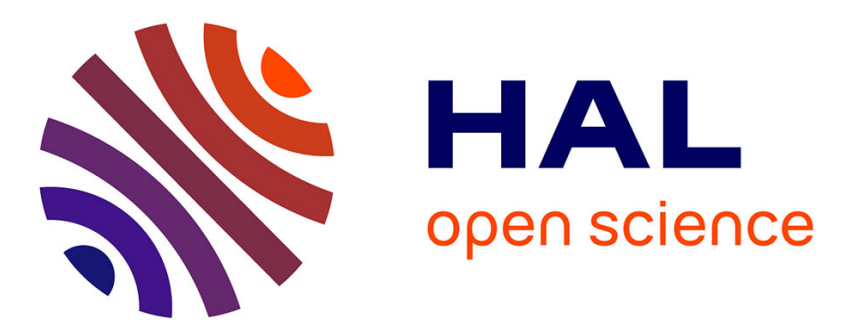

\title{
Structural characterization of water-bearing silicate and aluminosilicate glasses by high-resolution solid-state NMR
}

Eric Robert, Alan Whittington, Franck Fayon, Michel Pichavant, Dominique

Massiot

\section{To cite this version:}

Eric Robert, Alan Whittington, Franck Fayon, Michel Pichavant, Dominique Massiot. Structural characterization of water-bearing silicate and aluminosilicate glasses by high-resolution solid-state NMR. Chemical Geology, 2001, 174, pp.291-305. 10.1016/S0009-2541(00)00321-1 . hal-00089816

\section{HAL Id: hal-00089816 \\ https://hal-insu.archives-ouvertes.fr/hal-00089816}

Submitted on 20 Sep 2006

HAL is a multi-disciplinary open access archive for the deposit and dissemination of scientific research documents, whether they are published or not. The documents may come from teaching and research institutions in France or abroad, or from public or private research centers.
L'archive ouverte pluridisciplinaire HAL, est destinée au dépôt et à la diffusion de documents scientifiques de niveau recherche, publiés ou non, émanant des établissements d'enseignement et de recherche français ou étrangers, des laboratoires publics ou privés. 


\title{
Structural characterization of water-bearing silicate and aluminosilicate glasses by high-resolution solid-state NMR
}

\author{
Eric Robert ${ }^{1, \text {, a }}$, Alan Whittington ${ }^{2, \text {, a, , b }}$, Franck Fayon ${ }^{\mathrm{a}}$, Michel Pichavant ${ }^{\mathrm{c}}$ and \\ Dominique Massiot ${ }^{\text {a }}$
}

${ }^{a}$ Centre de Recherche sur les Matériaux à Haute Température-CNRS, 1D avenue de la Recherche Scientifique, 45071 Orléans cedex 2, France

${ }^{\mathrm{b}}$ Institut de Physique du Globe, 4 place Jussieu, 75252 Paris cedex 05, France

${ }^{\mathrm{c}}$ Centre de Recherche sur la Chimie et la Synthèse de Minéraux, CNRS, 45071 Orléans cedex 2, France - remplacé par UMR6113 - ISTO

\begin{abstract}
Various one- and two-dimensional high-resolution solid-state NMR techniques have been applied to hydrous silicate and aluminosilicate glasses: simple acquisition, cross-polarization (CP-MAS), heteronuclear correlation (HETCOR), dipolar dephasing, spin counting, doublequantum correlation, and rotational echo double resonance (REDOR). The comparison of the results obtained for sodium tetrasilicate and phonolite glasses suggests that the water incorporation mechanisms are qualitatively similar for these two compositions. From proton NMR experiments, we observe no evidence of proton clustering and a wide range of chemical shifts ranging from 0 to $16 \mathrm{ppm}$, even for the aluminosilicate phonolite glass, identifying at least three types of hydroxyl $(\mathrm{OH})$ protons in addition to molecular $\mathrm{H}_{2} \mathrm{O}$. This variety of $\mathrm{OH}$ groups can be discussed in terms of hydrogen bonding strength. For both compositions, the results indicate some depolymerization of the tetrahedral network, but the picture cannot be so simple as to completely exclude any of the different previously proposed models for water incorporation in silicate glasses.
\end{abstract}

Author Keywords : Silicate glass; Aluminosilicate glass; Hydrous glasses; Solid-state NMR; ${ }^{1} \mathrm{H} ;{ }^{23} \mathrm{Na} ;{ }^{27} \mathrm{Al} ;{ }^{29} \mathrm{Si}$; Dipolar interaction; Spin counting; Double-quantum correlation; HETCOR; CPMAS; REDOR 


\section{Introduction}

The physical properties of silicate and aluminosilicate melts and glasses (e.g., liquidus and glass transition temperatures, phase relations, viscosity, density) are strongly affected by small amounts of water dissolved under pressure and at high temperature (e.g., Burnham; Mysen; Dingwell; Richet and Richet). However, despite many previous studies, the mechanism of water dissolution in silicate melts is still a matter of discussion (McMillan, 1994). In situ measurements on hydrous melts are extremely difficult to perform, and up to now limited to Raman (Holtz et al., 1996) and near-infrared techniques (e.g., Nowak and Shen). The latter techniques have confirmed the proposal of Dingwell and Webb (1990) that water speciation changes upon heating through the glass transition, moving towards higher concentrations of hydroxyl $(\mathrm{OH})$ groups and lower concentrations of molecular water. However, the glass structure frozen in on cooling through the glass transition is the same as that of the liquid at the glass transition temperature, hence, the study of hydrous glasses constitutes a valuable step towards understanding the dissolution of water in silicate melts. Moreover, these glasses also have important technological applications such as nuclear waste glasses or fiber optic cables.

One of the most debated points is the question of whether or not the incorporation of water leads to the rupture of $\mathrm{Si}-\mathrm{O}-\mathrm{Si}$ and $\mathrm{Al}-\mathrm{O}-\mathrm{Si}$ bonds to form $\mathrm{Si}-\mathrm{OH}$ and/or $\mathrm{Al}-\mathrm{OH}$. While it is widely accepted that water depolymerizes the network of alkali silicate glasses (e.g., Kohn; $\mathrm{Xu}$ and Zotov), it is not at all clear that the same mechanism occurs in aluminosilicate glasses (Burnham; Mysen; Kohn; Kohn; Kohn; Kohn; Sykes and Sykes). Most of the models based on vibrational spectroscopic results propose such depolymerization (e.g., Stolper; Mysen and Remmele). However, a study of albite, nepheline and anorthite-quartz glasses, performed using a variety of NMR techniques, led to different conclusions (Kohn and Kohn). These authors did not find conclusive evidence for the presence of $\mathrm{Al}-\mathrm{OH}$ or $\mathrm{Si}-\mathrm{OH}$ in the hydrous samples and proposed a possible new interpretation of the vibrational data. Instead of depolymerization of the $\mathrm{T}-\mathrm{O}-\mathrm{T}$ network, they suggested that water dissolution involves a simple exchange of $\mathrm{Na}^{+}$for $\mathrm{H}^{+}$as charge-balancing cation for $\mathrm{AlO}_{4}{ }^{-}$tetrahedra (this chargebalancing $\mathrm{H}^{+}$can also be seen as a bridging $\mathrm{OH}$ group), and formation of $\mathrm{Na}(\mathrm{OH})$ complexes.

A recent ${ }^{17} \mathrm{O}$ NMR study observed a new peak in albite glass with $10 \mathrm{wt} . \%$ water, which was tentatively identified as $\mathrm{Si}-\mathrm{OH}$, but there remains the possibility that this new peak represents a protonated bridging oxygen (Xu et al., 1998). Despite many studies on this problem, it remains debated in the case of aluminosilicate compositions, and new advances in spectroscopic techniques are probably required to produce less equivocal results. Increasingly complex double-resonance experiments may be the key to this problem. The recent ${ }^{1} \mathrm{H} /{ }^{27} \mathrm{Al}$ and ${ }^{1} \mathrm{H} /{ }^{23} \mathrm{Na}$ TRAPDOR study of Zeng et al. (1999) investigated proton environments in several glasses on the joint $\mathrm{NaAlO}_{2}-\mathrm{SiO}_{2}$ and found three different proton $\mathrm{OH}$ resonances, which were all ascribed to the terminal $\mathrm{T}-\mathrm{OH}$ groups, suggesting depolymerization of the network by water.

Our aim in this paper is to establish the feasibility and use of a variety of possible NMR experiments that recently became available. We applied these methods to a hydrated sodium tetrasilicate and a synthetic iron-free phonolitic composition, with the aim of establishing the similarities and differences of structure and water incorporation mechanism in hydrous silicate and aluminosilicate glasses. The sodium tetrasilicate is a model compound, which has been previously studied by several techniques, including NMR (Schaller and Sebald, 1995), and the phonolite is an iron-free synthetic analogue of an alkali-rich volcanic rock, which has 
recently been studied by viscosity measurements (Whittington et al., 2000). It is difficult or impossible to obtain well-resolved spectra of iron-bearing compounds because the presence of paramagnetic centers induces severe line broadening. While several previous studies have concentrated on albite glass $\left(\mathrm{NaAlSi}_{3} \mathrm{O}_{8}\right)$, theoretically fully polymerized in the anhydrous state, the phonolite is a more complex aluminosilicate composition, which is partially depolymerized even when anhydrous. One aim of this study is to test whether results from albite are more generally applicable to other geologically relevant compositions.

\section{NMR background}

Solid-state NMR is a quickly progressing technique, sensitive to the environment of the selectively observed nucleus (Engelhardt and Schmidt and references therein). Observable nuclei have non-zero nuclear spins $\left(I=1 / 2\right.$ for ${ }^{1} \mathrm{H},{ }^{29} \mathrm{Si}$, or ${ }^{31} \mathrm{P} ; I=3 / 2$ for ${ }^{7} \mathrm{Li},{ }^{11} \mathrm{~B},{ }^{23} \mathrm{Na}$, or ${ }^{69,71} \mathrm{Ga}$; $I=5 / 2$ for ${ }^{17} \mathrm{O}$ or ${ }^{27} \mathrm{Al}$ ) (Table 1 ), and their respective sensitivities depend on their natural abundance, gyromagnetic ratios and quadrupolar momentum (non-zero when $I>1 / 2$ ). In an intense principal field $B_{0}$ (typically $\sim 10 \mathrm{~T}$ ), the selected nucleus is observed by applying a radio-frequency perturbation field oscillating at the Larmor frequency $v_{0}=\gamma B_{0}$ (where $\gamma$ is the gyromagnetic ratio, a constant for each nuclide) and registering the signal generated by the nuclear spins coming back to equilibrium. This signal (free induction decay (FID)) is then Fourier-transformed (FT) to obtain the frequency spectrum of the observed nucleus. The selectivity of the experiment comes from the large differences in Larmor frequency for the different nuclei, which allows selective excitation and recording of the spectra for each nuclei. NMR characterizes the perturbation of this resonance condition due to (a) the shielding of the principal field by bonding electrons (chemical shift anisotropy interaction), (b) the interaction between neighboring spins (dipolar interaction) or (c) the interaction of the electric field gradient at the nucleus position with the nuclear quadrupolar momentum (quadrupolar interaction) (Table 2). These perturbations are usually so small that they can be treated as first-order perturbations. The peak positions are expressed in ppm of the Larmor frequency compared to a reference compound. Nevertheless, quadrupolar interactions can become large enough to induce second-order effects that render the spectra of quadrupolar nuclei less resolved, and more difficult to model and understand. In the solid state, all these interactions are anisotropic, depending on the orientation of the crystallite in the principal field, and, consequently, the static spectra of powdered samples are broad and unresolved. Highresolution spectra can be obtained for solids by averaging the anisotropic part of the interaction by manipulating the sample with magic-angle spinning (MAS), or manipulating the spin system with radio-frequency pulses. This is the source of a large number of different experiments that aim at simplifying the spectra by removing or selecting the different anisotropic interactions. Under fast MAS, which mimics the motional narrowing of a liquid sample, both dipolar interactions and the chemical shift anisotropy are averaged, and the MAS NMR spectrum of a $I=1 / 2$ nucleus consists only of sharp peaks at the isotropic position. This position is directly characteristic of the coordination number, bond angles, and bond lengths around the observed nucleus. Quadrupolar interactions are reduced but not eliminated under fast MAS, but higher resolution can be obtained using two-dimensional MQ-MAS techniques, which combine MAS spinning and multiple quantum evolution (Frydman and Medek). Because solid-state NMR is mostly sensitive to the first-coordination spheres of the observed nuclei, it can still provide good resolution when going from a perfectly ordered crystalline compound to a more disordered amorphous or glassy material. 
Table 1. NMR observable nuclei with their main characteristics

\begin{tabular}{llll}
\hline Nucleus & $\begin{array}{l}\text { Nuclear } \\
\text { spin } I\end{array}$ & $\begin{array}{l}\text { Natural } \\
\text { abundance (\%) }\end{array}$ & $\begin{array}{l}\text { Larmor } \\
\text { frequency } \\
\text { at 9.4 T (MHz) }\end{array}$ \\
\hline${ }^{1} \mathrm{H}$ & $1 / 2$ & 99.99 & 400.2 \\
${ }^{29} \mathrm{Si}$ & $1 / 2$ & 4.7 & 79.5 \\
${ }^{23} \mathrm{Na}$ & $3 / 2$ & 100 & 105.8 \\
${ }^{27} \mathrm{Al}$ & $5 / 2$ & 100 & 104.2 \\
\hline
\end{tabular}

Table 2. Physical background and information linked to the different interactions that can be observed by solidstate NMR in silicate or aluminosilicate glasses

\begin{tabular}{|c|c|c|}
\hline Interaction & Physical background & Information \\
\hline $\begin{array}{l}\text { Dipolar } \\
\text { interaction }\end{array}$ & $\begin{array}{l}\text { Interaction between } \\
\text { neighboring spins }\end{array}$ & Distances \\
\hline $\begin{array}{l}\text { Chemical shift } \\
\text { anisotropy }\end{array}$ & $\begin{array}{l}\text { Shielding of principal } \\
\text { field by electrons }\end{array}$ & $\begin{array}{l}\text { Coordination } \\
\text { number } \\
\text { Bond angles and } \\
\text { distances }\end{array}$ \\
\hline $\begin{array}{l}\text { Quadrupolar } \\
\text { interaction }\end{array}$ & $\begin{array}{l}\text { Interaction between } \\
\text { electric field } \\
\text { gradient } \\
\text { and nucleus } \\
\text { quadrupolar } \\
\text { momentum }\end{array}$ & Geometry \\
\hline
\end{tabular}

Using one-dimensional solid-state experiments (fast MAS or MQ-MAS), it is thus possible to characterize the first-coordination sphere of the observed nucleus in glasses, but this is obtained at the cost of averaging the dipolar interaction that contains information on longer range order. This dipolar interaction is inversely proportional to the third power of the distance between interacting spins. Nevertheless, numerous solid-state one-dimensional experiments can benefit from the dipolar interaction and enable its characterization, while retaining the high resolution of MAS spectra: (a) cross-polarization (CP-MAS) transfers magnetization from abundant sensitive protons to a rare spin system (e.g., $\left\{{ }^{1} \mathrm{H}\right\}-{ }^{29} \mathrm{Si}$ ); (b) multiple-quantum experiments aim at acquiring indirectly the signature of groups of like spins coupled by dipolar interactions (e.g., ${ }^{1} \mathrm{H}$ pairs); (c) double resonance experiments (rotational echo double resonance (REDOR)) aim at selecting from MAS spectra the signature of nuclei, which are dipolar coupled to others (e.g., $\left\{{ }^{1} \mathrm{H}\right\}{ }^{29} \mathrm{Si},\left\{{ }^{1} \mathrm{H}\right\}-{ }^{23} \mathrm{Na},\left\{{ }^{1} \mathrm{H}\right\}-{ }^{27} \mathrm{Al}$ ). Finally, from these experiments, it is also possible to build multiple-dimension experiments that establish correlations between the spectra of different nuclei (heteronuclear correlation (HETCOR) ${ }^{1} \mathrm{H}-$ ${ }^{29} \mathrm{Si}$ ) or between double-quantum and single-quantum spectra (spectrum of pairs of like nuclei/spectrum of individual nuclei). 


\section{Experimental techniques}

\subsection{Sample compositions and preparation}

We selected two types of glasses: a model binary sodium silicate $\left(\mathrm{Na}_{2} \mathrm{O}-4 \mathrm{SiO}_{2}\right.$ further referred to as NS4) and a synthetic iron-free analog of phonolitic composition (further referred to as phonolite). The NS4 dry and hydrated glasses are simple compositions which have already been studied by several techniques (Schaller; Zotov and Zotov). The different environments of silicon $\left(\mathrm{Q}_{4}, \mathrm{Q}_{3}, \mathrm{Q}_{2}\right)$ are known to be partly resolved in the ${ }^{29} \mathrm{Si}$ MAS NMR spectra. In the dry glass, the network is partly depolymerized with a ratio of non-bridging oxygens to tetrahedral (network-forming) cations $(\mathrm{NBO} / \mathrm{T})$ of 0.5 , corresponding to a $\mathrm{Q}_{3} / \mathrm{Q}_{4}$ ratio of 1/1. The phonolite glass has a complex composition with an Si/Al ratio of about 2.5. Assuming that all the aluminum resides in tetrahedrally coordinated network former sites charge compensated by alkali and alkaline earths, the dry glass has an NBO/T of about 0.19 , and is thus more polymerized than the NS4 glass. The expected silicon environments range from $\mathrm{Q}_{4}$ to $\mathrm{Q}_{3}$ with possible $\mathrm{Al}$ as first tetrahedral neighbors.

The dry glass samples were synthesized from reagent grade oxides and melted at room pressure. The water-bearing glasses were melted at high temperature and pressure in internally heated high-pressure vessels and quenched isobarically. The hydration conditions and the water contents measured by Karl-Fischer titration are given in Table 3.

Table 3. Compositions and synthesis conditions for the anhydrous and hydrous glass of NS4 and phonolite with the measured NMR parameters. For $C_{Q \eta}$, "wid" indicates the half width of the quadrupolar coupling distribution. $C_{Q}=e^{2} q Q / h=e q V_{z z} / h ; \eta=\left|\left(V_{x x}-V_{y y}\right) / V_{z z}\right|$, $\mathrm{C}_{\mathrm{g} n}=\mathrm{C}_{\mathrm{g}} \sqrt{1+\eta^{2} / 3}$

\begin{tabular}{|c|c|c|c|c|}
\hline Sample & $\delta_{\mathrm{CS}}(\mathrm{ppm})$ & Width (ppm) & $C_{Q \eta}(\mathrm{MHz})$ & $C_{Q}$ width $(\mathrm{MHz})$ \\
\hline \multicolumn{5}{|c|}{$\begin{array}{l}\mathrm{NS} 4 \text { (mol\%) } \mathrm{SiO}_{2} 8 \mathrm{OO}, \mathrm{Na}_{2} \mathrm{O} 20, \mathrm{NBO} / \mathrm{T} 0.5 \\
\mathrm{NS} 4 \text { dry }(0 \text { wt } \% \mathrm{H}, \mathrm{O})\end{array}$} \\
\hline${ }^{29} \mathrm{Si} \mathrm{Q}_{4}$ & -105.6 & 14.0 & - & - \\
\hline${ }^{29} \mathrm{Si}_{3}$ & -92.0 & 11.3 & - & - \\
\hline${ }^{23} \mathrm{Na}$ & 3.9 & - & $3.2($ wid 0.7$)$ & 0.7 \\
\hline \multicolumn{5}{|c|}{ NS4 $1.28\left(2 \mathrm{kbar}, 1100^{\circ} \mathrm{C}, 1.28 \pm 0.07 \mathrm{wt} . \% \mathrm{H}_{2} \mathrm{O}\right)$} \\
\hline${ }^{29} \mathrm{Si}_{4}$ & -104.0 & 13.6 & - & - \\
\hline${ }^{29} \mathrm{Si}_{3}$ & -93.0 & 11.4 & - & - \\
\hline${ }^{29} \mathrm{Si} \mathrm{Q}_{2}$ & -83.4 & 10.7 & - & - \\
\hline${ }^{23} \mathrm{Na}$ & 3.4 & - & $3.2($ wid 0.7$)$ & 0.7 \\
\hline \multicolumn{5}{|c|}{ Phonolite (mol\%) $\mathrm{SiO}_{2} 65.4, \mathrm{Al}_{2} \mathrm{O}_{3} \mathrm{I2.7}, \mathrm{MgO} 3.1, \mathrm{CaO} 2.8, \mathrm{Na}_{2} \mathrm{O} 10.0, \mathrm{~K}_{2} \mathrm{O} 5.3, \mathrm{TiO}_{2}$ 0.7, $\mathrm{NBO} / \mathrm{TO} 0.19$} \\
\hline \multicolumn{5}{|c|}{ Phonolite dry $\left(0\right.$ wt. $\left.\% \mathrm{H}_{2} \mathrm{O}\right)$} \\
\hline${ }^{29} \mathrm{Si}$ & -94.6 & 15 & - & - \\
\hline${ }^{23} \mathrm{Na}$ & -10 & - & 2.35 (wid 0.6 ) & 0.5 \\
\hline${ }^{27} \mathrm{Al}$ & 61 & _- & 7.1 & 1.6 \\
\hline \multicolumn{5}{|c|}{ Phonolite $0.9\left(3 \mathrm{kbar}, 1300^{\circ} \mathrm{C}, 0.90 \pm 0.1\right.$ wt. $\left.\% \mathrm{H}_{2} \mathrm{O}\right)$} \\
\hline${ }^{29} \mathrm{Si}$ & -92.7 & 19 & - & - \\
\hline${ }^{23} \mathrm{Na}$ & -10 & - & 2.3 (wid 0.5 ) & 0.46 \\
\hline${ }^{27} \mathrm{Al}$ & 62 & - & 7.6 & 1.7 \\
\hline \multicolumn{5}{|c|}{ Phonolite $3.2\left(2 \mathrm{kbar}, 1200^{\circ} \mathrm{C}, 3.2 \pm 0.2\right.$ wt. $\left.\% \mathrm{H}_{2} \mathrm{O}\right)$} \\
\hline${ }^{29} \mathrm{Si}$ & -89.6 & 17 & - & - \\
\hline${ }^{23} \mathrm{Na}$ & -7 & - & 2.3 (wid 0.5$)$ & 0.48 \\
\hline${ }^{27} \mathrm{Al}$ & 61 & - & 6.0 & 1.2 \\
\hline
\end{tabular}




\subsection{NMR}

Sample preparation (sample crushing and MAS rotor filling) for NMR observation was carried out in an argon-filled dry-gloved box to avoid adsorption of moisture. High-resolution solid-state NMR experiments were acquired at room temperature and pressure using a Bruker DSX-400 spectrometer $\left(B_{0}=9.4 \mathrm{~T}\right)$, and 4-mm double-bearing $15 \mathrm{kHz}$ Bruker probe head. Spectra were externally referenced to TMS for ${ }^{29} \mathrm{Si}$ and ${ }^{1} \mathrm{H}, 1 \mathrm{M}$ aqueous $\mathrm{NaCl}$ for ${ }^{23} \mathrm{Na}$, and 1 $\mathrm{M}$ aqueous $\mathrm{Al}\left(\mathrm{NO}_{3}\right)_{3}$ for ${ }^{27} \mathrm{Al}$. Most experiments have been conducted at $9.4 \mathrm{~T}$ using an MAS spinning rate of 10 to $14 \mathrm{kHz}$, unless otherwise stated.

\section{Results}

\subsection{Single-dimension (1D) MAS NMR experiments}

Simple 1D MAS NMR spectra have been acquired for the different observable nuclei of our samples : ${ }^{29} \mathrm{Si},{ }^{23} \mathrm{Na},{ }^{27} \mathrm{Al}$, and ${ }^{1} \mathrm{H}$. As our samples were not enriched with paramagnetic impurities relaxation times were rather long, especially for ${ }^{29} \mathrm{Si}\left(T_{1}>1800 \mathrm{~s}\right)$. For silicon, we shall report the one-pulse spectra of the anhydrous glasses and the proton cross-polarized ${ }^{29} \mathrm{Si}$ (CP-MAS) spectra for the hydrous ones (see discussion below). These CP-MAS spectra are not quantitative as the signal of the different sites is a function of their average distance to protons. Reported spectra have been acquired for long contact times (typically $15 \mathrm{~ms}$ ).

We first consider the ${ }^{29} \mathrm{Si}$ spectrum of anhydrous NS4 glass, in which the silicate network is partly depolymerized $(\mathrm{NBO} / \mathrm{T}=0.5)$. This clearly shows the presence of two overlapping but partly resolved contributions in a 1/1 ratio (Fig. 1). These two contributions are ascribed to $\mathrm{Q}_{3}$ $\left(\delta_{\mathrm{CS}}=-92 \mathrm{ppm}\right)$ and $\mathrm{Q}_{4}\left(\delta_{\mathrm{CS}}=-106 \mathrm{ppm}\right)$, as predicted from the composition. Upon dissolution of water, we observe the growth of $\mathrm{Q}_{2}$ and $\mathrm{Q}_{3}$ intensities at the expense of the $\mathrm{Q}_{4}$ line $\left(\delta_{\mathrm{CS}}=-84,-94\right.$, and $-105 \mathrm{ppm}$, respectively). Although non-quantitative, this result unambiguously indicates that protons in the hydrous glasses are localized in an environment that is more depolymerized than the initial dry silicate network.

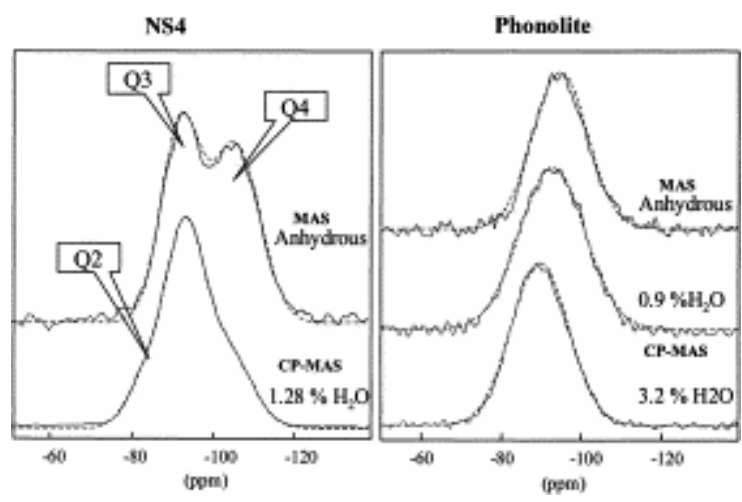

Fig. $1 .{ }^{29} \mathrm{Si}$ MAS (anhydrous) and CP-MAS (hydrous) spectra of NS4 and phonolite. Dashed lines are the fitted model spectra. 
In the ${ }^{23} \mathrm{Na}$ MAS NMR spectra (Fig. 2) of both anhydrous and hydrated samples, we observe a wide featureless peak, broadened due to second-order quadrupolar interactions, which does not appear to be affected by the introduction of water. MAS NMR ${ }^{23} \mathrm{Na}$ spectra have been modeled with a single component with distribution of chemical shifts and quadrupolar coupling, giving $\delta_{\mathrm{CS} \sim 4} \mathrm{ppm}$ and $C_{Q \eta \sim 3} \sim 2 \mathrm{MHz}(0.7 \mathrm{MHz}$ width) for these samples (Table 3). The ${ }^{1} \mathrm{H}$ MAS NMR spectrum of the hydrated sample shows three partly resolved contributions. The left part of the spectrum consists of at least two overlapping lines from 16 down to $8 \mathrm{ppm}$, while the right part of the spectrum can be described by a single line at $4 \mathrm{ppm}$ (Fig. 3). In a previous study on a glass of similar composition, these contributions were attributed to $\mathrm{OH}$ and molecular $\mathrm{H}_{2} \mathrm{O}$, respectively (Schaller and Sebald, 1995).

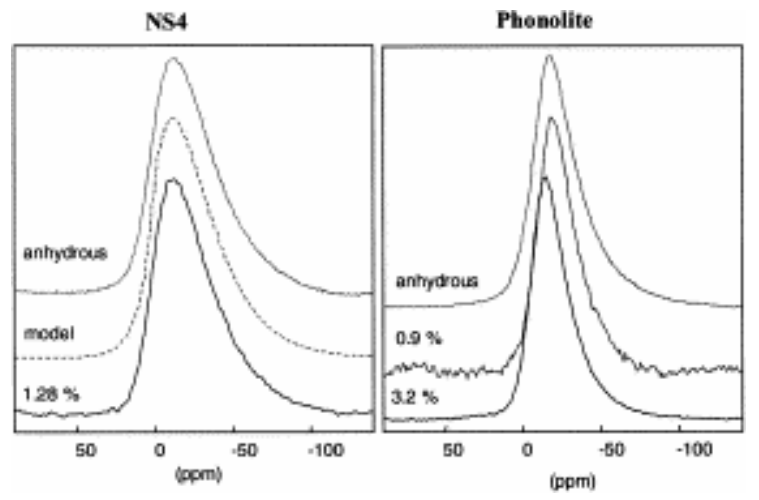

Fig. 2. ${ }^{23} \mathrm{Na}$ MAS spectra of NS4 and phonolite. The model dashed line illustrates the shape of the model component obtained by considering a distribution of the second order quadrupolar interaction (3.2 $\mathrm{MHz}$ with a distribution width of $0.7 \mathrm{MHz}$ ).

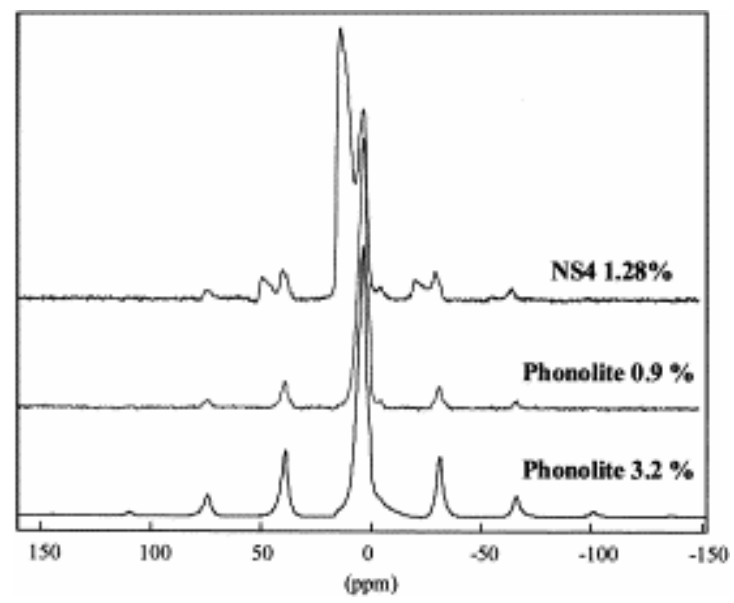

Fig. 3. ${ }^{1} \mathrm{H}$ MAS spectra of NS4 1.28\%, phonolite $0.9 \%$, and phonolite $3.2 \%$ samples. Spinning rate $14 \mathrm{kHz}$.

The phonolite glass structure is more complex, with a tetrahedral network made up of Si and charge compensated Al. Due to the variety of silicon environments ranging from $\mathrm{Q}_{4}$ to $\mathrm{Q}_{3}$ with possible aluminum substitution in the neighboring tetrahedra, no spectral resolution is observed in the ${ }^{29} \mathrm{Si}$ MAS or CP-MAS NMR spectra (Fig. 1). With increasing water content, 
we only observe a shift of the featureless line $\left(\delta_{\mathrm{CS}}=-94.6,-92.7\right.$, and $-89.6 \mathrm{ppm}$ for anhydrous, 0.9 and 3.2 wt. $\% \mathrm{H}_{2} \mathrm{O}$, respectively), together with a slight increase of the linewidth $(16,18$, and $19 \mathrm{ppm})$. As expected from composition, the ${ }^{27} \mathrm{Al}$ spectra of the phonolite glasses with different water contents clearly show that aluminum always occupies tetrahedral environments with a nearly constant isotropic chemical shift of $62 \pm 1$ ppm (Fig. 4). Nevertheless, at the highest water content $\left(3.2 \mathrm{wt} . \% \mathrm{H}_{2} \mathrm{O}\right)$, the shape of the ${ }^{27} \mathrm{Al}$ MAS NMR spectrum is strongly modified, becoming sharper and more symmetric. This is typical of a decrease of the average second-order quadrupolar interaction (measured by $C_{Q \eta}$ and its distribution width). It is remarkable that this strong modification of the quadrupolar coupling occurs at a constant average chemical shift. As observed for NS4, the ${ }^{23} \mathrm{Na}$ spectra of the different phonolite samples are broadened by second-order quadrupolar interaction, with a noticeable sharpening for the highest water content (Fig. 2). The three samples have similar chemical shift positions $\left(-10,-10\right.$, and $-7 \mathrm{ppm}$ for anhydrous, 0.9 and 3.2 wt. $\% \mathrm{H}_{2} \mathrm{O}$, respectively) and mean quadrupolar couplings (2.4, 2.3, and $2.3 \mathrm{MHz}$ with width $0.6,0.5$, and $0.5 \mathrm{MHz}$ ). The main differences are the decrease of chemical shift for the highest water content and the slightly larger distribution of quadrupolar coupling for the anhydrous sample. In contrast with the NS4 hydrated glass, the MAS NMR ${ }^{1} \mathrm{H}$ proton spectra of the hydrated phonolites consist of a single rather sharp contribution at $\sim 4$ ppm (Fig. 3). This is attributed to both $\mathrm{OH}$ and $\mathrm{H}_{2} \mathrm{O}$ contributions, which are unresolved in this experiment. Spinning sidebands are more intense for the highest water content, which indicates greater homonuclear dipolar interaction between protons.

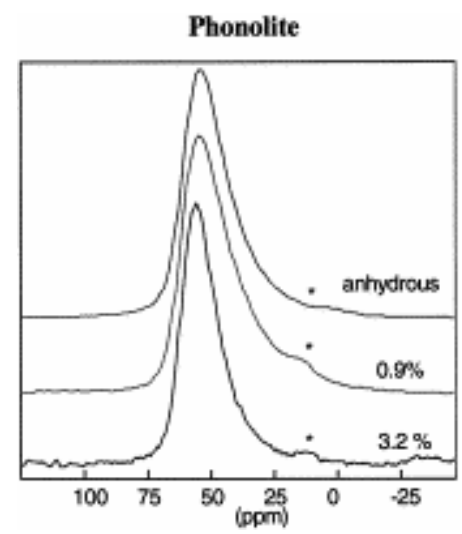

Fig. $4 .{ }^{27} \mathrm{Al}$ MAS spectra of phonolite samples, the $\left(^{*}\right)$ signals an artifact due to $\mathrm{Al}$ in the $\mathrm{ZrO}_{2}$ rotor.

\section{2. ${ }^{1} \mathrm{H}$ dipolar dephasing}

The available MAS spinning rates $(15 \mathrm{kHz})$ do not enable a complete averaging of the homonuclear $\mathrm{H}-\mathrm{H}$ dipolar interaction, which limits the spectral resolution. This incomplete averaging gives rise to incomplete refocusing of the signal in a Hahn-echo experiment for the protons undergoing strong homonuclear dipolar coupling and can be used to suppress these components from the ${ }^{1} \mathrm{H}$ spectrum in the ${ }^{1} \mathrm{H}$ dipolar dephasing experiment (Bronnimann et al., 1988). Spectra have been acquired for NS4 and phonolite with dephasing times of $66 \mu$ s up to $30 \mathrm{~ms}$ (Fig. 5). 


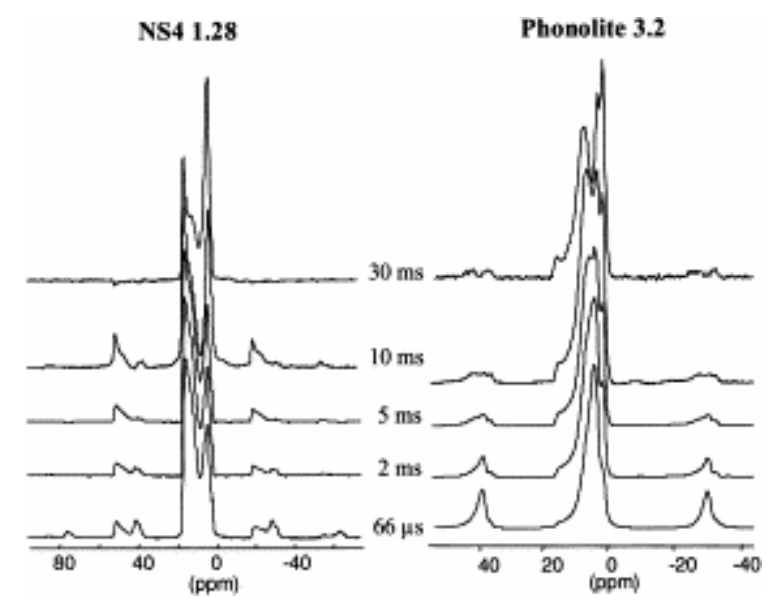

Fig. 5. Dipolar dephasing spectra of NS4 1.28 and phonolite 3.2 at various echo times. Spinning rate $14 \mathrm{kHz}$.

For the NS4 sample, we observe very few changes in the ${ }^{1} \mathrm{H}$ spectrum with increasing dipolar dephasing time. At very long times, we slightly improve the resolution of the high chemical shift lines (16 down to 8 ppm contribution). This implies that the different proton populations undergo similar dipolar coupling. In contrast, the ${ }^{1} \mathrm{H}$ dipolar dephased spectra for phonolite (3.2 wt. $\% \mathrm{H}_{2} \mathrm{O}$ ) show a marked reduction in intensity and change in pattern over the same range of delay times (Fig. 5b). The single broad line at $4 \mathrm{ppm}$ observed in the $1 \mathrm{D}$ spectrum becomes separated into at least three distinct components, which have individual chemical shifts from $\sim 0$ to $\sim 16 \mathrm{ppm}$. These components should correspond to a variety of relatively uncoupled protons, suggesting there should be at least three different $\mathrm{OH}$ environments in this glass, extending to large chemical shift values ( $16 \mathrm{ppm})$, which are usually attributed to strongly hydrogen bonded environments (Brunner and Sternberg, 1998).

\section{3. ${ }^{1} \mathrm{H}$ multiple quantum experiments}

Having identified the existence of a range of different strengths of coupling between protons, the next step is to obtain information about their longer-range ordering (of different $\mathrm{OH}$ and/or $\mathrm{H}_{2} \mathrm{O}$ groups). To do this, it is necessary to selectively enhance or detect the effects of dipolar interactions, since these interactions are directly related to the distances between nuclei. We applied multiple quantum dipolar techniques that allow indirect detection of the characteristic resonances of groups of coupled protons (Emsley and Pines, 1994 and Hafner and references therein).

\subsection{Spin-counting experiment}

A group of $n$-coupled protons can give rise to an indirectly detectable $n$-quantum signal using a suitable pulse sequence. It has recently been shown to be possible to achieve this even under MAS (Geen et al., 1999). In our systems, both NS4 and phonolite, we could only efficiently generate double-quantum coherences, with a low signal corresponding to four quanta. This excludes the possibility of clustering in proton rich domains in these glasses. 


\subsection{Double-quantum-filtered correlation experiments}

Given the possibility of efficiently generating the resonance of a pair of dipolar coupled protons (double-quantum coherence) it is possible to design a two-dimensional doublequantum-filtered correlation experiment. In this experiment, all intensity arises from pairs of protons (individual uncoupled protons do not show up) and is positioned in the twodimensional graph at the intersection of the chemical shifts of the individual members of the pair (Hafner and Spiess, 1998 and references therein).

For NS4, the three sites observed on the 1D MAS spectrum are also seen in the doubledimension (2D) spectrum and intensity is spread over all the possible correlations (Fig. 6). A very specific feature is observed for the 4 ppm line: it exhibits intense, on diagonal, aligned spinning sidebands. Since the strong dipolar coupling between the protons in molecular $\mathrm{H}_{2} \mathrm{O}$ is likely to give rise to such sidebands, the $4 \mathrm{ppm}$ contribution is probably due (at least partly) to molecular water. It is known from other studies that at room temperature water molecules are likely to be mobile (rotation around $\mathrm{C} 2$ axis) in glasses (Eckert and Riemer et al., submitted). This would result in making equivalent the two protons while retaining part of the dipolar interaction and explain the "on diagonal" signal that we observe at 4 ppm. Finally, the lack of intensity on the diagonal at high chemical shift indicates that most $\mathrm{OH}$ groups, which are closely spatially related are also structurally inequivalent. This does not exclude the possibility that part of the $4 \mathrm{ppm}$ line could also correspond to $\mathrm{OH}$ groups.
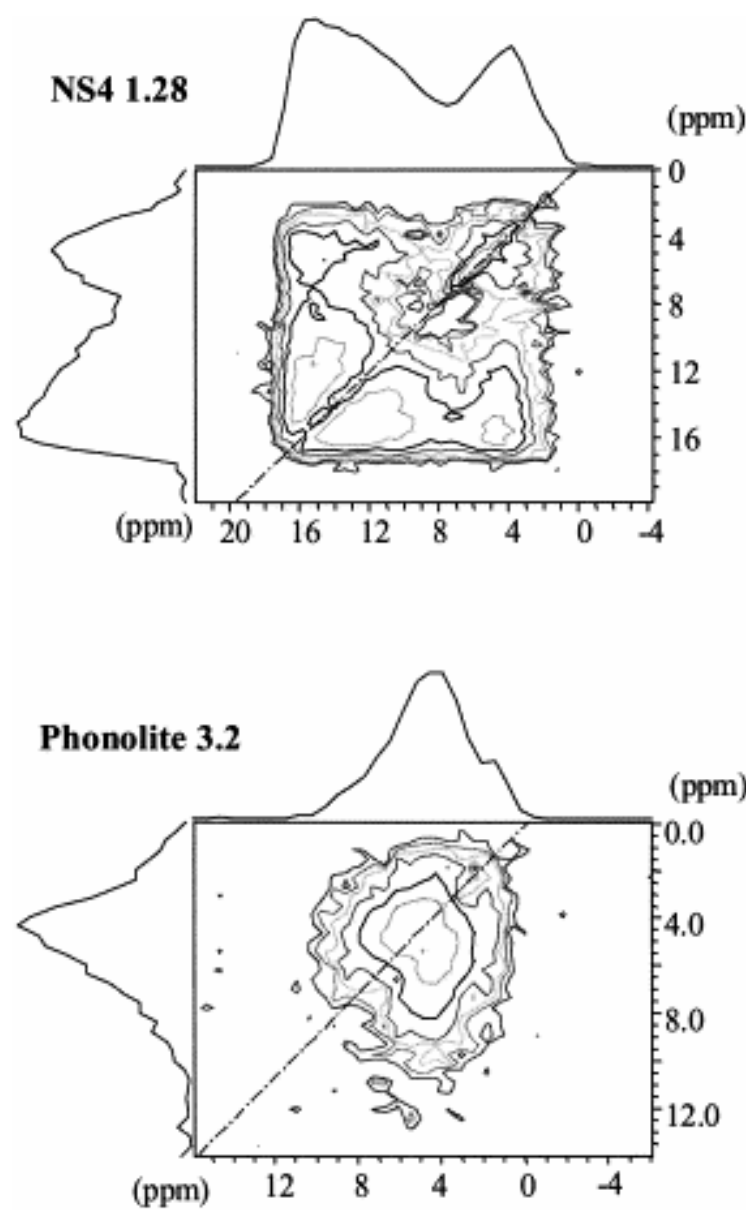

Fig. 6. ${ }^{1} \mathrm{H}$ MAS autocorrelation spectra through a 2 quanta filter (C7 dipolar recoupling sequence) for NS4 1.28 and Phonolite 3.2 spinning at $10 \mathrm{kHz}$. 
As expected from the less-resolved 1D spectrum, results for the phonolite with 3.2 wt. $\% \mathrm{H}_{2} \mathrm{O}$ are less clear. As in the 1D spectra, the range of chemical shifts apparent in the phonolite are restricted to the range 2 to $10 \mathrm{ppm}$, although components up to $16 \mathrm{ppm}$ were identified in the dipolar dephasing spectra and attributed to weakly coupled protons. Signal intensity is smeared across the diagonal, with spinning sidebands again present for the $\sim 4 \mathrm{ppm}$ contribution and ascribed to mobile water molecules. As for the case of NS4, we observe a lack of intensity on the diagonal at higher chemical shifts and this indicates a continuous distribution of pairs of spatially related but inequivalent protons from $\mathrm{OH}$ groups.

Having investigated homonuclear dipolar interactions between protons, we will now investigate heteronuclear dipolar interactions between protons and other nuclei. As mentioned above, heteronuclear dipolar interaction is weak and can be averaged out by MAS, which is necessary to obtain resolved spectra. This interaction can be studied by double resonance techniques like CP-MAS, which makes use of the remaining dipolar interaction, or REDOR, which selectively reintroduces $\mathrm{H}-\mathrm{X}$ dipolar interaction during an echo experiment).

\section{6. $\left\{{ }^{1} \mathrm{H}\right\}-{ }^{29} \mathrm{Si}$ CP-MAS and HETCOR}

CP-MAS is an efficient method for transferring magnetization from an abundant sensitive nucleus $\left({ }^{1} \mathrm{H}\right)$ to a diluted low sensitivity one $\left({ }^{29} \mathrm{Si}\right)$. It provides improved sensitivity and selects nuclei, which are related by dipolar coupling. The CP-MAS experiment can be acquired as a $1 \mathrm{D}$ experiment or as a 2D experiment (HETCOR), which provides a crosscorrelation of the spectra of the two nuclei. Unfortunately, this experiment does not apply well to quadrupolar nuclei like ${ }^{27} \mathrm{Al}$ or ${ }^{23} \mathrm{Na}$, and we report only results obtained with ${ }^{29} \mathrm{Si}$.

The CP-MAS experiment involves three steps : (1) excitation of ${ }^{1} \mathrm{H}$; (2) contact time; and (3) acquisition of the ${ }^{29} \mathrm{Si}$ spectrum. The key to the experiment is the contact time, typically a few milliseconds, which is the time given to the spin system to transfer the magnetization from ${ }^{1} \mathrm{H}$ to ${ }^{29} \mathrm{Si}$. The growth of the ${ }^{29} \mathrm{Si}$ signal will thus be a function of the duration of the contact and of the intensity of the dipolar coupling between each ${ }^{29} \mathrm{Si}$ and the ${ }^{1} \mathrm{H}$ bath. The HETCOR twodimensional experiment is acquired by introducing a supplemental evolution time between steps (1) and (2). Fig. 1 already showed application of CP-MAS to hydrous NS4 with resolution of the three lines ascribed to $\mathrm{Q}_{2}, \mathrm{Q}_{3}$, and $\mathrm{Q}_{4}$. It is possible to analyze the growth of each signal with increasing contact time, which will indicate the degree of dipolar coupling between $\mathrm{Si}$ and protons. As expected, the quickest signal growth is observed for $\mathrm{Q}_{2}$ sites (reaching a maximum at a contact time of about $7 \mathrm{~ms}$ ), and the slowest is observed for $\mathrm{Q}_{4}$ sites $(\max >20 \mathrm{~ms}$ ), which thus appear to be the closest and farthest from protons, respectively.

The $\left\{{ }^{1} \mathrm{H}\right\}-{ }^{29} \mathrm{Si}$ HETCOR experiment (Fig. 7), which correlates the proton spectrum to the silicon spectrum, can refine this analysis by directly revealing links between different proton sites and different silicon sites. This is demonstrated by the spectrum presented in Fig. 7a, which was acquired at a short contact time $(2 \mathrm{~ms})$ to minimize the spin diffusion in the proton bath and thus obtain better selectivity at the cost of sensitivity. First, we can remark that the ${ }^{1} \mathrm{H}$ spectrum ( $\left.\omega 1\right)$ dimension of the two-dimensional spectrum is missing intensity on the line at $\approx 4 \mathrm{ppm}$ when compared to the 1D spectrum. This implies that some protons at this chemical shift do not cross-polarize with silicon. A complete picture of the two-dimensional data set can be obtained by modeling the CP-MAS spectrum, fixing positions and line-widths 
of the $\mathrm{Q}_{2}, \mathrm{Q}_{3}$, and $\mathrm{Q}_{4}$ lines. Each slice of the silicon spectrum is then fitted by adjusting the amplitude of the three contributions. The result of this modeling is presented in Fig. $7 \mathrm{~b}$ and clearly shows that while $\mathrm{Q}_{2}$ and $\mathrm{Q}_{3}$ silicon sites are correlated to the whole range of ${ }^{1} \mathrm{H}$ sites, $\mathrm{Q}_{4}$ silicon sites only take intensity from the ${ }^{1} \mathrm{H}$ line at $4 \mathrm{ppm}$. It is very unlikely that water molecules could better cross-polarize to $\mathrm{Q}_{4}$ than to $\mathrm{Q}_{3}$ and $\mathrm{Q}_{2}$, and, therefore, the 4-ppm line should partly signal $\mathrm{OH}$ groups in a polymerized environment.
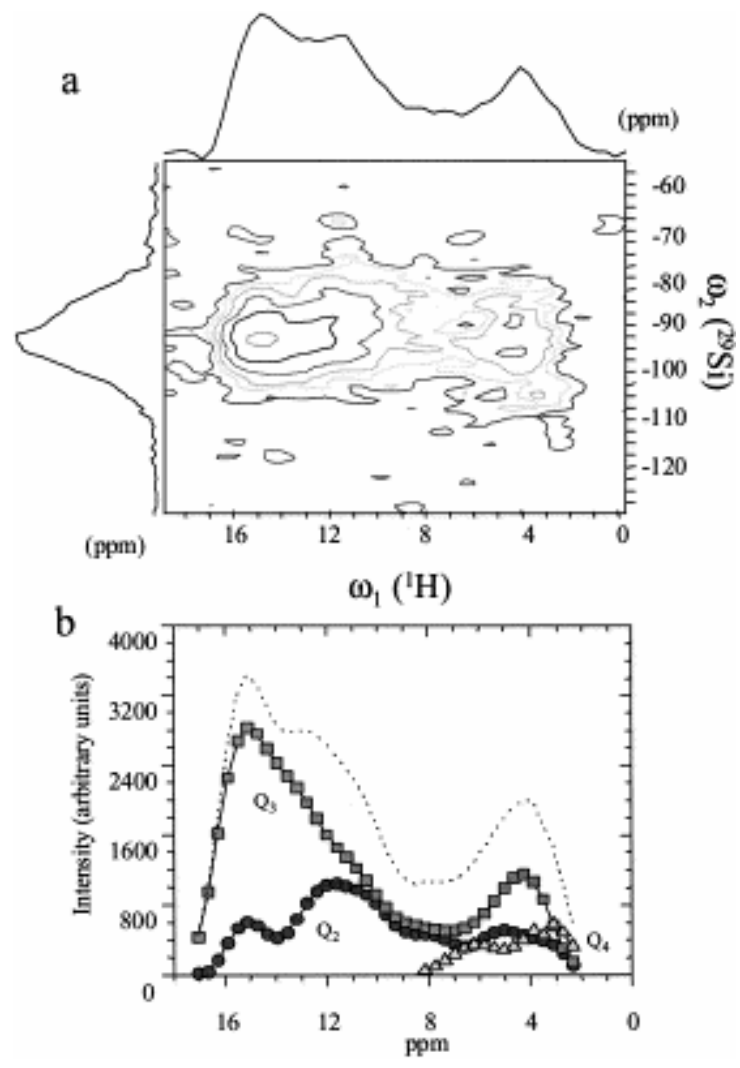

Fig. 7. (a) $\left\{{ }^{1} \mathrm{H}\right\}-{ }^{29} \mathrm{Si}$ HETCOR correlation and (b) deconvolution of each slice of the spectra as a function of ${ }^{1} \mathrm{H}$ chemical shift showing the spectra of protons coupled to $\mathrm{Q}_{2}, \mathrm{Q}_{3}$, and $\mathrm{Q}_{4}$.

The experiments carried out on hydrous phonolite samples do not provide as much information as in the case of the simple NS4 system. Their CP-MAS $\left\{{ }^{1} \mathrm{H}\right\}{ }^{29} \mathrm{Si}$ spectra consist of a single broad line whose profile does not depend on contact time, and the HETCOR spectrum does not show significant modification as a function of the position in the ${ }^{1} \mathrm{H}$ dimension.

\section{7. $\left\{{ }^{1} \mathrm{H}\right\}-{ }^{29} \mathrm{Si},\left\{{ }^{1} \mathrm{H}\right\}-{ }^{23} \mathrm{Na},\left\{{ }^{1} \mathrm{H}\right\}-{ }^{27} \mathrm{Al}$, REDOR}

Although the HETCOR experiment does not work well with quadrupolar nuclei $\left({ }^{23} \mathrm{Na}\right.$ and ${ }^{27} \mathrm{Al}$ ), we can observe heteronuclear dipolar couplings between ${ }^{1} \mathrm{H}$ and quadrupolar nuclei under MAS using the REDOR experiment (Gullion and Schaefer, 1989). This experiment was originally developed to accurately measure distances between the two labeled (selectively enriched) nuclei of an ideally isolated pair of spins in organic compounds. REDOR is a difference experiment that measures the modification of the echo intensity on the observed nuclei $\mathrm{X}$ due to irradiation of the second nuclear spin $\mathrm{H}$ that selectively reintroduces the $\mathrm{X}-\mathrm{H}$ dipolar coupling. Due its relative simplicity, its applicability can be extended to abundant 
quadrupolar nuclear spins $\left({ }^{27} \mathrm{Al},{ }^{23} \mathrm{Na}\right)$ in inorganic materials (Montouillout and Magnenet) even if the obtained information remains qualitative. The REDOR results are presented as normalized difference intensities for each resolved contribution vs. recoupling time (Fig. 8). The more rapidly the signal intensity for a given nucleus rises, the closer that nucleus is to the protons. In the case of NS4, curves can be measured not only for $\mathrm{Na}$ but also for the individual $\mathrm{Q}_{n}$ species of ${ }^{29} \mathrm{Si}$. The most rapid rise is seen for $\mathrm{Q}_{2}$, corroborating the CP-MAS result that protons are nearer to $\mathrm{Q}_{2}$ or more numerous in its neighborhood than to other types of Si. Na and $\mathrm{Q}_{3}$ behave similarly, but are farther from protons than $\mathrm{Q}_{2}$, while the curve for $\mathrm{Q}_{4}$ rises the slowest, indicating that these silicon nuclei are farthest from protons. Results of the same experiment applied to the two phonolite glasses show less pronounced differences between the different nuclei. The sample containing 0.9 wt. $\% \mathrm{H}_{2} \mathrm{O}$ shows almost identical behavior for $\mathrm{Na}, \mathrm{Al}$, and $\mathrm{Si}$ (undifferentiated), suggesting that there is no difference between these nuclei in their average distance to protons between these nuclei. The sample containing 3.2 wt. $\% \mathrm{H}_{2} \mathrm{O}$ shows a slightly slower response for $\mathrm{Si}$ than for $\mathrm{Na}$ and $\mathrm{Al}$, but, again, the different nuclei show quite similar responses.

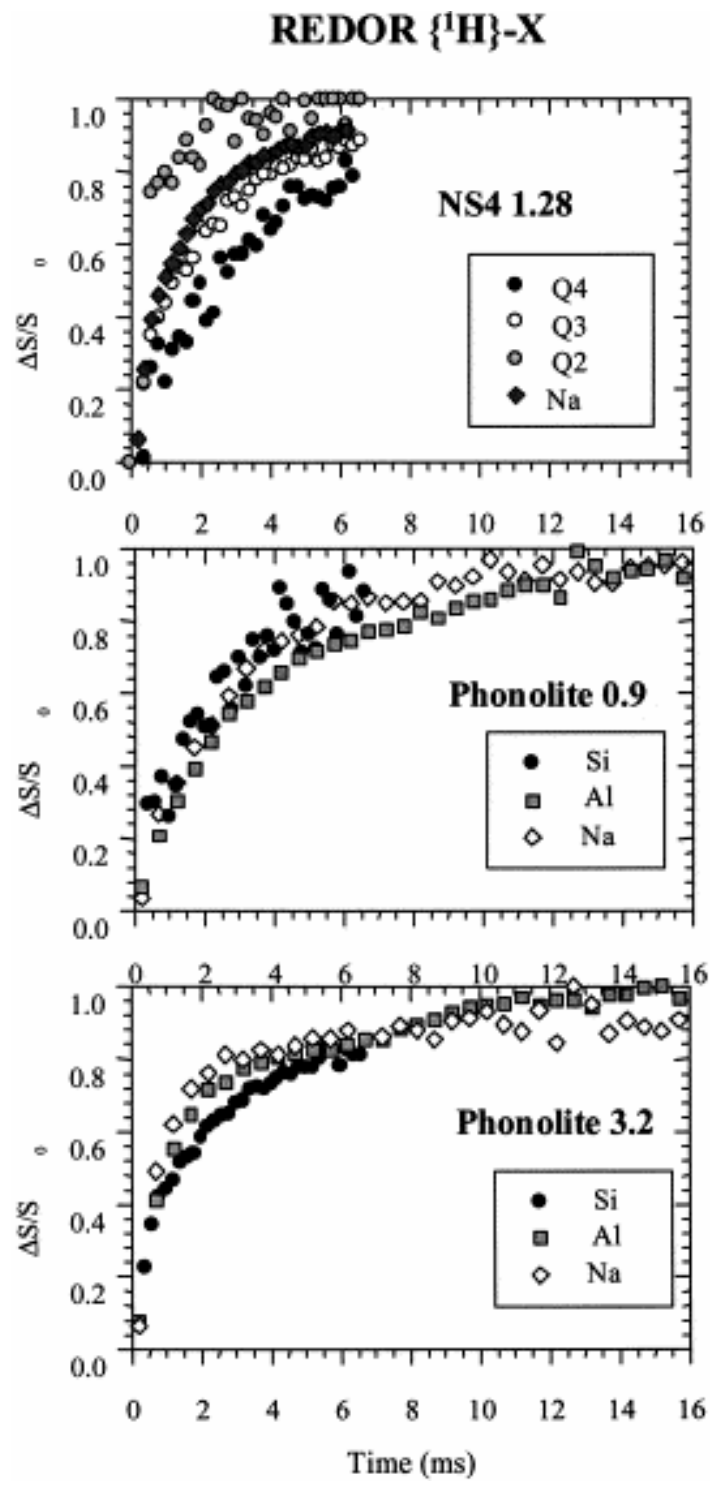

Fig. 8. REDOR curves for NS4 (grey circles: $\mathrm{Q}_{2}$; white circles: $\mathrm{Q}_{3}$; black circles: $\mathrm{Q}_{4}$; and diamond Na), Phonolite 0.9, and Phonolite 3.2 (black circles: Si; white diamonds: Na; and squares: Al). 


\section{Discussion}

\subsection{Sodium tetrasilicate}

For NS4, there is clear evidence from the single-pulse ${ }^{29} \mathrm{Si}$ MAS spectra in Fig. 1 (MAS and CP-MAS) for the growth of the $\mathrm{Q}_{2}$ and $\mathrm{Q}_{3}$ peaks, at the expense of the $\mathrm{Q}_{4}$ peak, signaling a net depolymerization of the silicate network in the nearby environment of protons, on addition of water. The reaction may be summarized as:

$$
\mathrm{H}_{2} \mathrm{O}+\mathrm{Si}-\mathrm{O}-\mathrm{Si}=2 \mathrm{Si}-\mathrm{OH}
$$

This mechanism was proposed by Burnham (1975) for albite glass, supported by infrared studies of water speciation in aluminosilicate glasses (Stolper, 1982), and confirmed by NMR studies of hydrated NS4 (Kohn; Kohn; K; Schaller and Zotov) and neutron diffraction (Zotov et al., 1996). In further agreement with these studies, we have also found evidence for some water dissolved as molecular $\mathrm{H}_{2} \mathrm{O}$. The ${ }^{1} \mathrm{H}$ MAS spectra show two main contributions, the first at $\sim 4 \mathrm{ppm}$ and the second at higher chemical shift (16 down to $8 \mathrm{ppm}$ ), the latter consisting of at least two different lines. Part of the 4-ppm contribution shows spinning sidebands and strong autocorrelation in the double-quantum-filtered ${ }^{1} \mathrm{H}$ dipolar correlation experiment, indicating strong dipolar coupling between two equivalent protons, as would be anticipated in a rotating $\mathrm{H}_{2} \mathrm{O}$ molecule. The other protons (pertaining to the whole spectral width) show neither autocorrelation nor spinning sidebands, and signal a distribution of pairs of unlike protons that should be ascribed to weaker $\mathrm{OH}-\mathrm{OH}$ pairs. This assignments partly concur with those of Schaller and Sebald (1995), based on ${ }^{1} \mathrm{H}$ MAS and ${ }^{1} \mathrm{H}$ MAS CRAMPS spectroscopy, but our interpretation is that only part of the 4-ppm line can be unambiguously ascribed to molecular $\mathrm{H}_{2} \mathrm{O}$. This is supported by our observation that $\mathrm{Q}_{4}$ silicon species crosspolarizes from this line (HETCOR experiment). While the relative distances from individual protons to ${ }^{29} \mathrm{Si}$ can be probed consistently by varying contact time in the CP-MAS experiment or varying the recoupling time in the REDOR experiment, it can only be assessed from REDOR experiments in the case of a quadrupolar nucleus. ${ }^{23} \mathrm{Na}$ appears to have a rising behavior similar to that of $\mathrm{Q}_{3}$ species, which could possibly be linked to one $\mathrm{OH}$ group. This behavior differs from that of the $\mathrm{Q}_{2}$ species, which could be linked to two $\mathrm{OH}$. As $\mathrm{Q}_{3}$ is the dominant Si contribution, this means that sodium does not see more protons in its close neighborhood than silicon does, and, therefore, protons play a typical network modifying role and depolymerize the silicon network.

\subsection{Phonolite}

Interpretation of results from the phonolite is much less clear-cut, in part because it is a much more complex composition. The most significant structural difference is the participation of $\mathrm{Al}$, as well as $\mathrm{Si}$ in the formation of an aluminosilicate network, and the concomitant increase in the number of chemical environments seen by each of these nuclei $\left(\mathrm{Q}_{3}\right.$ and $\mathrm{Q}_{4}$ species with possible substitution of $\mathrm{Al}$ as first neighbor). Resolution of separate $\mathrm{Q}$ species in ${ }^{29} \mathrm{Si} \mathrm{NMR}$ spectra of albite glasses has proved impossible (Kohn and Zavel), and the spectra in Fig. 1 show this to be case for the phonolite also. The chemical shift distribution increases slightly upon hydration, and average chemical shifts move to less shielded values with increasing water content, as was the case for NS4. These data suggest depolymerization of the aluminum-silicon network upon hydration. This is noticeably different to what was observed 
in albite, which showed no change in average chemical shift with increasing water content (Kohn et al., 1989b). From proton NMR, we showed that there is a much wider distribution of chemical shift than observed in the simple single-pulse experiment, as the dipolar dephasing experiment reveals a wide range of different lines up to $16 \mathrm{ppm}$. The $\mathrm{OH}$ and $\mathrm{H}_{2} \mathrm{O}$ contributions appear to strongly overlap mostly around $4 \mathrm{ppm}$. No contrast was obtained from the HETCOR experiment but REDOR shows very similar rising behavior for the three observed nuclei $\left({ }^{23} \mathrm{Na},{ }^{27} \mathrm{Al}\right.$, and $\left.{ }^{29} \mathrm{Si}\right)$, at least for low water contents. Hence, consistently with what we observed for NS4, we consider that all nuclei see the same average proton surrounding and that the dissolution of water leads to a depolymerization of the network. At higher water content, there seems to be an indication that the ${ }^{29} \mathrm{Si}$ REDOR signal rises slightly slower. In the model previously proposed by Kohn et al. (1989b), protons would be preferentially associated with $\mathrm{Al}$ and $\mathrm{Na}$ even at low water content, and this should appear in the REDOR experiments.

\subsection{Quadrupolar nuclei}

Some additional information could be expected from the interpretation of the spectra of the two observable quadrupolar nuclei ${ }^{23} \mathrm{Na}$ and ${ }^{27} \mathrm{Al}$. Two sources of broadening could be invoked: distribution of isotropic chemical shift and distribution of quadrupolar interaction. In simple cases, they could possibly be analyzed with a systematic use of the MQ-MAS experiment (Frydman and Medek). However, multiple field/spinning rate experiments show that the distribution of quadrupolar interaction is likely to be dominant under our observation conditions. The sharpening of both ${ }^{23} \mathrm{Na}$ and ${ }^{27} \mathrm{Al}$ lines upon hydration is well established, even if the evaluation of the quadrupolar parameters is highly model dependent. It seems to be mostly linked to a reduction of the mean quadrupolar coupling (Kohn; Kohn; Kohn and Schmidt). This is very similar to what is observed for zeolite structures where hydration diminishes the $\mathrm{Al}$ quadrupolar coupling. If we consider that most of the EFG viewed by $\mathrm{Al}$ or $\mathrm{Na}$ is due to point charges in the network, this could be understood as a relaxation of longrange order constraints. This is in strong contrast with what is observed for ${ }^{17} \mathrm{O}$ in covalent, low coordination number environments, where most of the quadrupolar interaction comes from the geometry of the binding orbitals (Grandinetti et al., 1995).

\subsection{Hydrogen bonding}

It is known that strength and geometry of hydrogen bonds influence proton chemical shift, deuterium quadrupolar coupling or infrared absorption frequencies (Brunner and Sternberg, 1998). The high values of proton chemical shifts that we observe directly in NS4 or in dipolar dephasing experiments in phonolite can be interpreted in these terms.

Several different correlations have been reported, based on studies of crystalline hydrates where bond lengths can be investigated by other means. Eckert et al. (1988) fitted available experimental data with the relation:

$\delta_{\mathrm{H}, \mathrm{iso}}(\mathrm{ppm})=79.05-255 d_{\mathrm{OH} \ldots \mathrm{O}}(\mathrm{nm})$

Strictly speaking, the chemical shift should be inversely proportional the bond polarization energy, and hence to bond lengths, but empirical equations assuming direct proportionality provide similarly good fits over relatively wide ranges of chemical shift. Brunner and Sternberg (1998) fitted a larger database with the following relation: 
$\delta_{\mathrm{H}, \text { iso }}(\mathrm{ppm})=4.65 / r_{\mathrm{HB}}(\mathrm{nm})-17.4$

where $r_{\mathrm{HB}}$ is the H... $\mathrm{O}$ distance, rather than the $\mathrm{OH} \ldots \mathrm{O}$ distance of Eq. (2). To allow direct comparison with previous studies, we will use Eq. (2) in the following discussion.

In NS4, there are distinct signals for molecular water at $4 \mathrm{ppm}$, corresponding to an O---H...O bond length of $0.294 \mathrm{~nm}$. It has been argued above that intensity at this chemical shift does not result entirely from molecular water, so that some $\mathrm{OH}$ is also hydrogen bonded with a similar bond length, and, hence, strength. These two signals may result from hydrogen bonding between water and $\mathrm{Si}-\mathrm{OH}$ species as described for hydrous silica glass by Kohn et al. (1989a).

Much higher chemical shifts ( 8 to $16 \mathrm{ppm}$ ) are observed directly in NS4 or through dipolar dephasing experiments in phonolite. These would correspond to hydrogen bond lengths of about 0.28 and $0.25 \mathrm{~nm}$ and could be related to the weak vibration at $2350 \mathrm{~cm}^{-1}$ observed in the Raman spectrum of NS4 glass containing $1 \mathrm{wt} . \% \mathrm{H}_{2} \mathrm{O}$ by McMillan and Remmele (1986). They attributed this signal, corresponding to a hydrogen bond length of about $0.26 \mathrm{~nm}$, to intratetrahedral hydrogen bonding between $\mathrm{SiOH}$ groups and NBO. These authors also identified a band extending from a maximum at about 2700 down to $2500 \mathrm{~cm}^{-1}$, corresponding to $\mathrm{OH} . . . \mathrm{O}$ bond lengths of about $0.265 \mathrm{~nm}$. Neither band was seen in the Raman spectra of silica glass, and intensity at these chemical shifts was not observed in a ${ }^{1} \mathrm{H}$ MAS study of silica glass by Kohn et al. (1989a), indicating that NBO must be involved.

To try to better understand the high proton chemical shifts that we measured for both compositions, we can refer to the literature. From a multinuclear MAS NMR study, Kohn et al. (1989b) ruled out more than a very small fraction $(<1 \%)$ of silicon atoms being in $\mathrm{Q}_{3}-\mathrm{OH}$ groups in hydrous albite glasses. Xu et al. (1998), making use of the newly developed MQMAS experiment applied to ${ }^{17} \mathrm{O}$, identified a line in hydrous NS4 glass ascribed to $\mathrm{SiOH}$. These authors also observed an apparent increase in intensity at the same position for hydrous albite glasses. This signal was small and obscured by the nearby Al-O-Si signal, which is much more intense, and while no firm conclusions were drawn, it seems possible that at least a small amount of $\mathrm{Si}-\mathrm{OH}$ may be present in hydrous albite. In contrast with albite, some NBO are already present in the anhydrous NS4 and phonolite glasses prior to hydration. The question then arises of the attribution of the 8 to $16 \mathrm{ppm} \mathrm{H}$ lines that we observe in NS4 and phonolite glasses and that preferentially cross-polarize to the depolymerized part of the network $\left(\left\{{ }^{1} \mathrm{H}\right\}-{ }^{29} \mathrm{Si}\right.$ HETCOR). Such chemical shifts were reported neither in hydrous silica nor in hydrous albite glasses (using simple experiments). Our results are in agreement with a $\mathrm{SiOH}$ group hydrogen bonded to a NBO as depicted by McMillan and Remmele (1986). This confirms that at least some of the protons act as network modifiers.

Nevertheless, this discussion is based on a largely simplified picture of the aluminosilicate network. For anhydrous glasses, it is known that bridging oxygens can have modifier cations in their neighborhood, and that the environment of a NBO is much more complex than a single link to one specific modifier (Florian and Stebbins). Our results do not exclude any of the previously proposed mechanisms and are consistent with recent viscosity measurements, which suggest that several mechanisms may operate simultaneously (Whittington et al., 2000). This preliminary investigation indicates directions for future advances in the understanding of hydrous glass structures using high-resolution solid-state NMR. 
Most previous studies have dealt with large amounts ( $\sim 5$ to $10 \mathrm{wt} . \%$ ) of dissolved water added to a given composition. This introduces two types of difficulties: (i) a large proportion of protons remain in water molecules and dominate in spectroscopic studies and (ii) if protons act as network modifiers, it would be of interest to work at constant NBO/T ratio.

\section{Conclusions}

We have studied two anhydrous and hydrous silicate (sodium tetrasilicate) and aluminosilicate (synthetic iron free phonolite analog) glasses by a variety of high-resolution solid-state NMR techniques. While the usual one-dimensional NMR experiments provide information on the structure of the first-coordination shell of the observed nuclei, some more sophisticated experiments, which take advantage of the reintroduction of the homonuclear $(\mathrm{H}-\mathrm{H})$ or heteronuclear $(\mathrm{H}-\mathrm{X})$ dipolar interaction, can now characterize longer-range order: CP-MAS, HETCOR, $\mathrm{H}$ dipolar dephasing, $\mathrm{H}$ spin counting, $\mathrm{H}$ double-quantum correlation, and H-X REDOR. It clearly appears that these proton-based NMR experiments provide a new insight to the mechanism of dissolution of water.

The comparison of results obtained for sodium tetrasilicate and phonolite glasses suggests that the water incorporation mechanisms are qualitatively similar for these two compositions. Due to the qualitative nature of many of the more complex experiments, quantitative comparisons are beyond the scope of the present study. From proton NMR experiments, we observe no evidence of proton clustering and a wide range of chemical shifts ranging from 0 to $16 \mathrm{ppm}$, even for the aluminosilicate phonolite glass, identifying at least three types of $\mathrm{OH}$ protons in addition to molecular $\mathrm{H}_{2} \mathrm{O}$. This variety of $\mathrm{OH}$ groups can be interpreted in terms of hydrogen bonding strength. For both compositions, we see evidence of depolymerization of the tetrahedral network, and the picture is more complicated than described by previously proposed models.

This preliminary work opens the way for more detailed studies of the network modifier role of the proton, especially at low water content. High-resolution proton-based solid-state NMR experiments should provide efficient tools for studying local and medium range order in these glasses (e.g., Zeng et al., 1999).

\section{Acknowledgements}

We thank Thomas Riemer and Pascal Richet for helpful discussions and Simon Kohn, Don Dingwell, and an anonymous reviewer for their comments. We acknowledge financial support from the CNRS Chemistry Department, Région Centre and European Community Training and Mobility Research program "Hydrous silicate melts in situ at high temperature and pressure" TMR ERBFMRX 960063. 


\section{References}

Burnham, C.W., 1975. Water and magmas, a mixing model. Geochim. Cosmochim. Acta 52 , pp. 2659-2669.

Burnham, C.W., 1979. The importance of volatile constituents. In: Yoder, H.S., Editor, , 1979. The Evolution of the Igneous Rocks: Fiftieth Anniversary Perspectives, Princeton Univ. Press, pp. 439-482.

Bronnimann, C.E., Zeigler, R.C. and Maciel, G.E., 1988. Proton NMR study of dehydration of the silica gel surface. J. Am. Chem. Soc. 110, pp. 2023-2026.

Brunner, E. and Sternberg, U., 1998. Solid-state NMR investigations of the nature of hydrogen bonds. J. Progr. Nucl. Magn. Res. Spectrosc. 32, pp. 21-57.

Dingwell, D.B. and Webb, S.L., 1990. Relaxation in silicate melts. Eur. J. Mineral. 2, pp. 427-449.

Dingwell, D.B., Romano, C. and Hess, K.-U., 1996. The effect of water on the viscosity of a haplogranitic melt under $\mathrm{P}-\mathrm{T}-\mathrm{X}$ conditions relevant to silicic volcanism. Contrib. Mineral. Petrol. 124, pp. 19-28.

Eckert, H., Yesinowski, J.P., Stolper, E.M., Stanton, T.R. and Holloway, J., 1987. The state of water in rhyolitic glasses. A deuterium NMR study. J. Non-Cryst. Solids 93, pp. 93-114.

Eckert, H., Yesinowski, J.P., Silver, L.A. and Stolper, E.M., 1988. Water in silicate glasses: quantitation and structural studies by ${ }^{1} \mathrm{H}$ solid echo and MAS-NMR methods. J. Phys. Chem. 92, pp. 2055-2064.

Emsley, L., Pines, A., 1994. Lectures on Pulsed NMR, Proceeding of the International School of Physics "Enrico Fermi”, Societa Italiana di Fisica CXXIII.

Engelhardt, G. and Michel, D., 1987. High Resolution Solid State NMR of Silicates and Zeolites, Wiley, New York.

Florian, P., Vermillion, K.E., Grandinetti, P.J., Farnan, I. and Stebbins, J.F., 1996. Cation distribution in mixed alkali disilicate glasses. J. Am. Chem. Soc. 118, p. 3493.

Frydman, L. and Harwood, J.S., 1995. Isotropic spectra of half-integer quadrupolar spins from bidimensional magic-angle spinning NMR. J. Am. Chem. Soc. 117, pp. 5367-5368.

Geen, H., Graf, R., Heindrichs, A.S.D., Hickman, B.S., Schnell, I., Spiess, H.W. and Titman, J.J., 1999. Spin counting with fast MAS. J. Magn. Reson. 138, pp. 167-172.

Grandinetti, P.J., Baltisberger, J.H., Farnan, I., Stebbins, J.F., Werner, U. and Pines, A., 1995. Solid-state ${ }^{17} \mathrm{O}$ magic-angle and dynamic-angle spinning NMR study of the $\mathrm{SiO}_{2}$ polymorph coesite. J. Phys. Chem. 99, p. 12341.

Gullion, T. and Schaefer, J., 1989. In: Warren, S., Editor, , 1989. Advances in Magnetic Resonance vol. 13, Academic Press, San Diego. 
Hafner, S. and Spiess, H.W., 1998. Advanced solid-state NMR spectroscopy of strongly dipolar coupled spins under fast magic angle spinning. Concepts Magn. Reson. 10, pp. 99128.

Holtz, F., Bény, J.M., Mysen, B.O. and Pichavant, M., 1996. High-temperature Raman spectroscopy of silicate and aluminosilicate hydrous glasses: implications for water speciation. Chem. Geol. 128, pp. 25-39.

Kohn, S.C., Dupree, R. and Smith, M.E., 1989. Proton environments and hydrogen bonding in hydrous silicate glasses from proton NMR. Nature 337, pp. 539-541.

Kohn, S.C., Dupree, R. and Smith, M.E., 1989. A multinuclear resonance study of the structure of hydrous albite glasses. Geochim. Cosmochim. Acta 53, pp. 2925-2935.

Kohn, S.C., Dupree, R. and Mortuza, M.G., 1992. The interaction between water and aluminosilicate magmas. Chem. Geol. 96, pp. 399-409.

Kohn, S.C., Smith, M.E. and Dupree, R., 1994. Comment on "a model for $\mathrm{H}_{2} \mathrm{O}$ solubility mechanisms in albite melts from infrared spectroscopy and molecular orbital calculations" by D. Sykes and J.D. Kubicki. Geochim. Cosmochim. Acta 58, pp. 1377-1380.

Kohn, S.C., Smith, M.E., Dirken, P.J., van Eck, E.R.H., Kentgens, A.P.M. and Dupree, R., 1998. Sodium environments in dry and hydrous albitic glasses: improved ${ }^{23} \mathrm{Na}$ solid state NMR data and their implications for water dissolution mechanisms. Geochim. Cosmochim. Acta 62, pp. 79-87.

Kümmerlen, J., Merwin, L.H., Sebald, A. and Keppler, H., 1992. Structural role of $\mathrm{H}_{2} \mathrm{O}$ in sodium silicate glasses: results from ${ }^{29} \mathrm{Si}$ and ${ }^{1} \mathrm{H}$ NMR spectroscopy. J. Phys. Chem. 96, pp. 6405-6410.

Magnenet, C., Massiot, D., Klur, I. and Coutures, J.P, 2000. Characterization of alumino silicate on rutile surface by high-resolution solid state NMR. J. Mater. Sci. 35, pp. 115-121.

McMillan, P. and Remmele Jr., R.L., 1986. Hydroxyl sites in SiO2 glass: a note on infrared and Raman spectra. Am. Mineral. 71, pp. 772-778.

McMillan, P., 1994. Water solubility and speciation models. Min. Soc. Am. Rev. Min. 30, pp. 131-156.

Medek, A., Harwood, J.S. and Frydman, L., 1995. Multiple-quantum magic-angle spinning NMR: a new method for the study of quadrupolar nuclei in solids. J. Am. Chem. Soc. 117, pp. 12779-12787.

Montouillout, V., Massiot, D., Douy, A. and Coutures, J.P., 1999. Characterization of $\mathrm{MgAl}_{2} \mathrm{O}_{4}$ precursor powders prepared by aqueous routes: ${ }^{27} \mathrm{Al}$ MAS, MQ-MAS and ${ }^{27} \mathrm{Al}-$ $\left\{{ }^{1} \mathrm{H}\right\}$ REDOR investigations. J. Am. Ceram. Soc. .

Mysen, B.O., Virgo, D. and Seifert, F.A., 1982. The structure of silicate melts: implications for chemical and physical properties of natural magmas. Rev. Geophys. Space Phys. 20, pp. $353-383$. 
Mysen, B.O. and Virgo, D., 1986. Volatiles in silicate melts at high pressure and temperature: 2. Water in melts along the join $\mathrm{NaAlO}_{2}-\mathrm{SiO}_{2}$ and a comparison of solubility mechanisms of water and fluorine. Chem. Geol. 57, pp. 333-358.

Nowak, M. and Behrens, H., 1995. The speciation of water in haplogranitic glasses and melts determined by in situ near-infrared spectroscopy. Geochim. Cosmochim. Acta 59, pp. 34453450 .

Remmele, R., Stanton, T., McMillan, P. and Holloway, J., 1986. Raman spectra of hydrous glasses along the quartz-albite join. EOS (Trans. Am. Geophys. Union) 67, p. 1274

Richet, P., Lejeune, A.M., Holtz, F. and Roux, J., 1996. Water and the viscosity of andesite melts. Chem. Geol. 128, pp. 185-197.

Richet, P. and Polian, A., 1998. Water as a dense ice-like component in silicate glasses. Science 281, pp. 396-398.

Riemer, T., Schmidt, B., Behrens, H., Dupree, R., submitted. $\mathrm{H}_{2} \mathrm{O} / \mathrm{OH}$ ratio determination in hydrous silicate glasses by static proton NMR and the effect of chemical shift anisotropy.

Schaller, T. and Sebald, A., 1995. One- and two-dimensional ${ }^{1} \mathrm{H}$ magic-angle spinning experiments on hydrous silicate glasses. Solid State Nucl. Magn. Reson. 5, pp. 89-102.

Schmidt, B.C., Riemer, T., Kohn, S.C., Behrens, H. and Dupree, R., 2000. The effects of water on the structure of quartz-albite glasses quenched from hydrous melts at high $\mathrm{P}$ and $\mathrm{T}$ : an NMR spectroscopic study. Geochim. Cosmochim. Acta.

Schmidt-Rohr, K. and Spiess, H.W, 1994. Multi-Dimensional Solid State NMR and Polymers, Academic Press, New York.

Shen, A. and Keppler, H., 1995. Infrared spectroscopy of hydrous silicate melts to $1000^{\circ} \mathrm{C}$ and 10 kbar: direct observation of $\mathrm{H}_{2} \mathrm{O}$ speciation in a diamond-anvil cell. Am. Mineral. 80, pp. 1335-1338.

Stebbins, J.F., Oglesby, J.V. and Xu, Z., 1997. Disorder among network-modifier cations in silicate glasses: new constraints from triple-quantum ${ }^{17} \mathrm{O}$ NMR. Am. Mineral. 82, pp. 11161124.

Stolper, E., 1982. Water in silicate glasses: an infrared spectroscopic study. Contrib. Mineral. Petrol. 81, pp. 1-17.

Sykes, D. and Kubicki, J.D., 1993. A model for $\mathrm{H}_{2} \mathrm{O}$ solubility mechanisms in albite melts from infrared spectroscopy and molecular orbital calculations. Geochim. Cosmochim. Acta 57, pp. 1039-1052.

Sykes, D. and Kubicki, J.D., 1994. Reply to the comment by Kohn, S.C., Smith, M.E. and Dupree, R. on "a model for $\mathrm{H}_{2} \mathrm{O}$ solubility mechanisms in albite melts from infrared spectroscopy and molecular orbital calculations". Geochim. Cosmochim. Acta 58, pp. 13811384. 
Whittington, A., Richet, P., Linard, Y. and Holtz, F., 2000. The viscosity of hydrous phonolites and trachytes. Chem. Geol..

Xu, Z., Maekawa, Oglesby, J.V. and Stebbins, J.F., 1998. Oxygen speciation in hydrous silicate glasses: an oxygen-17 NMR study. J. Am. Chem. Soc. 20, pp. 9894-9901.

Zavel'sky, V.O., Bezmen, N.I. and Zharikov, V.A., 1998. Water in albite glasses: OH-groups, isolated molecules, and clusters. J. Non-Cryst. Solids 224, pp. 225-231

Zeng, Q., Nekvasil, H. and Grey, C.P., 1999. Proton environments in hydrous aluminosilicate glasses: a ${ }^{1} \mathrm{H}$ MAS, ${ }^{1} \mathrm{H} /{ }^{27} \mathrm{Al}$, and ${ }^{1} \mathrm{H} /{ }^{23} \mathrm{Na}$ TRAPDOR NMR study. J. Phys. Chem. $B$ 103, pp. $7406-7415$.

Zotov, N., Keppler, H., Hannon, A.C. and Soper, A.K., 1996. The effect of water on the structure of silicate glasses - a neutron diffraction study. J. Non-Cryst. Solids 202, pp. 153163.

Zotov, N. and Keppler, H., 1998. The influence of water on the structure of hydrous sodium tetrasilicate glasses. Am. Mineral. 83, pp. 823-834. 